Folia Histórica del Nordeste, $\mathbf{N}^{\circ} 19$ (Resistencia, 2011) IIGHI, IH - CONICET, UNNE

\title{
A ORGANIZAÇÃO DE COMUNIDADES CÍVICAS NO ESPAÇO DA COLONIZAÇÃO AGRÍCOLA DO SUL DO BRASIL (1850-1930)
}

\author{
The Civic Community Organizations and the Agricultural Colonization Spaces of \\ Southern Brazil (1850-1930)
}

\section{Erneldo Schallenberger}

\section{Resumen}

As comunidades cívicas surgiram entre os teuto-brasileiros dos espaços de colonização agrícola do sul do Brasil como resultado de um esforço de viabilização da vida associativa, entendida como forma de organização social capaz de combater a pobreza, de compensar a ausência de políticas públicas e de redes de mercado que favorecessem a promoção do bem-estar social e do desenvolvimento local. As associações locais e as redes de cooperação desempenharam, neste caso, o papel de promoção e de inclusão social dos grupos de imigrantes, que careciam de mecanismos de participação política, de inserção na economia de mercado e de segurança e bem-estar social. Tratava-se, sobretudo, do entendimento de que as adversidades sociais poderiam ser superadas em base as teorias reformadoras humanistas, buscando nos fundamentos da cultura os elementos da participação cívica.

$$
<\text { Inmigración }><\text { Asociativismo }><\text { Comunidades cívicas }>
$$

\begin{abstract}
The civic communities have emerged among the Teutonic-Brazilian agricultural colonization of southern Brazil as an effort to rescue the associative life, understood as a form of social organization capable to fight poverty, compensate the absence of public policies and market networks for the promotion of social welfare and local development. Local associations and networks of cooperation have played in this case, the role of promotion and social inclusion of immigrant groups, which lacked mechanisms for political participation, integration into the market economy and security and social welfare. This was mainly on the understanding that social adversity could be overcome based on humanistic theories of reform, seeking the foundations of the culture elements of civic participation.
\end{abstract}

$<$ Immigration $><$ Associations $>$ Civic communities $>$ 


\section{Introdução}

No presente estudo investiga-se os elementos de coesão societária que contribuíram, no período formativo do espaço agrícola do sul do Brasil, para o desenvolvimento do associativismo, em suas variadas formas, e para a organização de comunidades cívicas.

As comunidades cívicas requerem o engajamento pró-ativo dos sujeitos no sentido de buscarem um bem público desejado. A comunidade cívica requer e conduz para a cooperação. Nela o ideal não está dado, mas deve ser conquistado, o que induz o sujeito à participação. A virtude cívica parece residir, segundo Putnam (2007, p. 101), no reconhecimento e na busca perseverante de um bem público à custa de todo o interesse puramente individual e particular. As necessidades individuais, cercadas pelos limites da sua operacionalização, são maximizadas pela cooperação, onde os sujeitos da ação somam esforços para a conquista do seu bem-estar na medida em que o de todos for alcançado (Omnia omnibus). A postura e a atitude cívicas se expressam pela participação democrática, pela confiança e pela renúncia pessoal e tolerância ao outro em vista da conquista de um bem maior ou de uma causa comum. É assim que se apresenta uma possibilidade teórico-explicativa para dar conta da complexa construção social nos espaços da imigração. Entende-se a partir dela que entre os teuto-brasileiros, as comunidades cívicas surgiram do esforço de viabilização da vida associativa, entendida como forma de organização social capaz de fazer frente aos desafios socioambientais e de combater a pobreza e a deficitária assistência dada nas condições de vida em que se encontravam no sul do Brasil.

Se ao conceito de cultura for atribuído o sentido de uma unidade de estilo, como quer Nietzsche, ou se a sua noção for associada aos produtos do homem e às diferenças nacionais ou particulares de grupos, como realça Nisbet (1982, p. 14 e 15), a representação dos interesses dos teuto-brasileiros encontrou, certamente, no capital cultural, enquanto expressão de poder de força, no entendimento de Bourdieu (2001), uma referência basilar. Apesar das variáveis culturais internas à etnia, relativas aos credos, às formas de inserção social e aos diferentes lugares de origem dos imigrantes, a língua e os operadores simbólicos da cultura eram referentes fundamentais para que os sujeitos se percebessem inseridos e integrados em elos socioculturais (OLIVEIRA, 2006). O desafio era converter este capital cultural em capital social, o que significaria, segundo Putnam (2007), fazer com que os indivíduos despertassem para o desenvolvimento de ações conjuntas que primassem pela confiabilidade e pelo compromisso mútuo de buscarem na realização de objetivos comuns e do bem público a sua auto-realização. Os interesses próprios deveriam se encontrar com os comuns para que a organização de comunidades cívicas se tornasse viável.

Tocqueville (1998), ao analisar a sociedade norte-americana, acentua que as associações livres foram definitivas para a construção do modelo de sociedade fundado nos princípios democráticos de participação política, articulação econômica e de inserção social. No sul do Brasil, a cultura política de participação não caracteriza 
necessariamente o envolvimento democrático dos indivíduos, como quer Macpherson (1977), mas expressa, em muitas circunstâncias, um arranjo institucional marcado por relações verticais e promovido pelas lideranças da imigração, com o propósito de arregimentar os sujeitos sociais para a participação na vida comunitária e associativa.

As associações desempenhariam, neste caso, o papel de promoção e de inclusão social dos grupos de imigrantes, que careciam de mecanismos de participação política, de inserção na economia de mercado e de segurança e bem-estar social. Tratava-se, sobretudo, do entendimento de que as adversidades sociais poderiam ser superadas em base as teorias reformadoras humanistas, buscando nos fundamentos da cultura os elementos da participação cívica (FIGUEIREDO, 2001).

O presente artigo desenvolve sua abordagem focada em três fenômenos típicos que acompanharam os processos de imigração e colonização do sul do Brasil: o fenômeno do desarranjo socioambiental e institucional; o fenômeno da instabilidade político-territorial; e, o fenômeno do mercado.

\section{O fenômeno do desarranjo socioambiental e institucional: experiências singulares de São Lourenço e Dona Francisca}

Em face da desorganização político-institucional das colônias, o desafio de arranjos institucionais, ou seja, padrões organizativos, que dessem sustentabilidade para os espaços sociais e culturais, característicos das comunidades de imigrantes do sul do Brasil, e para funcionamento de sistemas produtivos foram desencadeadas ações de mobilização social com fins cívicos.

Experiências desta natureza podem ser identificadas nas colônias de São Lourenço, no sul do atual estado do Rio Grande do Sul, e de Dona Francisca (Joinville), no norte do atual estado de Santa Catarina, através de diferenciadas faces de inserção social e de participação cívica. Em São Lourenço foram induzidas relações verticais de ação participativa em razão do líder e fundador da Colônia, Jacob Rheingantz, ter percebido as dificuldades que cercavam a organização dos espaços coloniais. Selecionou, através de colaboradores, os colonos e firmou contrato com o governo imperial de compra e venda dos lotes coloniais, em 1856, comprometendo-se a povoá-los com alemães, suíços ou belgas, mediante a contrapartida de uma subvenção de $15 \$ 000$ por pessoa maior de 10 anos (COARACY, 1957, p. 39). As garantias sociais e econômicas do empreendimento de Rheingantz foram buscadas num arranjo institucional pelo qual instituiu um Conselho, que reunia os principais representantes dos colonos em torno do Diretor, para expor e discutir questões de interesse coletivo. Para Coaracy (1957, p. 63) "este processo de resolver os problemas pela ação coordenada dos próprios colonos sob a orientação do Diretor tornou-se uma necessidade”. A prática política certamente despertou o interesse cívico. Na proporção do crescimento populacional, dos desafios sociais daí decorrentes e da ausência do Estado no atendimento das demandas sociais, notadamente da segurança, foram buscadas soluções que resultaram na organização de uma incipiente comunidade cívica. 
Em 1862, os moradores de São Lourenço se reuniram na casa do Diretor "para o fim de zelar pelo bem geral e pela ordem", para o que entendiam necessária a eleição de um Inspetor para cada picada. Elaboraram uma ata, transcrita por Coaracy (1957, pp. 70-73), que traduz um estatuto para regular as relações sociais da Colônia. Agendas relativas à infra-estrutura (conservação de estradas), à segurança e à ordem social, ao registro de nascimentos, óbitos e casamentos e à freqüência obrigatória nas escolas constavam das obrigações dos inspetores. Dos deveres dos colonos constava: a obrigatoriedade de contribuir para a conservação das estradas; apresentar-se ao Inspetor para conciliação, em caso de desavenças; comunicar ao Inspetor os casos de nascimento, óbito e casamento; respeitar e acatar os editais do Inspetor; e, em se tratando de fundação de qualquer escola ou igreja, o fato deveria ser firmado em um regulamento, com a anuência do Diretor. Os inspetores eram eleitos a cada dois anos.

O estilo hierárquico e centralizador refletem a concepção de uma sociedade conservadora, referenciada em cânones patriarcais.

D. Francisca (Joinville) resultou da negociação de um latifúndio do norte de Santa Catarina entre Christian Mathias Schröeder e Cia e o Príncipe de Joinville, que detinha um dote real herdado em decorrência do casamento com a princesa brasileira Dona Francisca. A concessão da área para a colonização reservava cláusulas de direito ao Príncipe e estabelecia obrigações para a colonizadora - Colonizations-Verein -, constituída por ações, dentre as quais se destacam: introduzir progressivamente 1.500 colonos; pagar-lhes as passagens; garantir crédito aos colonos mais pobres e a possibilidade do seu pagamento através da prestação de serviços; providenciar ferramentas e moradia; isenção dos colonos de qualquer tributo pelos 10 primeiros anos, além de garantir-lhes a alimentação por, no mínimo, um ano (FICKER, 1965). O regime jurídico da Colônia esteve, pois, assegurado por contrato. A introdução de imigrantes e as cláusulas sociais que cercaram a organização do núcleo colonial de D. Francisca revelam uma realidade peculiar no processo da colonização do sul do Brasil.

Tanto Ficker (1965) quanto Almeida e Piazza (1979) evidenciam em suas construções históricas que, no início da colonização, as habitações eram coletivas e que, em virtude de problemas relacionados com a alta de preços, falta de dinheiro e alcoolismo, houve tumultos que só foram contornados pela Direção da Colônia mediante a convocação de uma reunião popular, em julho de 1852. A reunião tornouse expressão de participação democrática, uma vez que deliberou pela escolha de 11 representantes de povo, que tinham a incumbência de elaborar a Carta de Joinville, ou "Lei Fundamental", para regular a vida da Colônia. A Lei foi aprovada em assembléia popular, em 23 de janeiro de 1853, e passou a representar, na expressão de Almeida e Piazza (1979) "uma verdadeira Constituição da Colônia". A Constituição previa uma organização política em torno de uma Comuna. A Comuna representava o poder legislativo e nomeava, para o mandato de um ano, o Conselho Comunal, integrado por 5 membros e 2 suplentes, aos quais era atribuído poder absoluto. Cabia ao Conselho Comunal indicar os Chefes de Sessão e um Secretário. Estas funções eram pagas, para que os encarregados pudessem se dedicar integralmente "aos interesses dos colonos 
no interior e exterior." O poder judicial era exercido por um juiz de paz e 12 colonos, indicados para o exercício da função por um ano. Não havia direito de apelação das sentenças. Além da aplicação da lei, era, também, da incumbência deste fórum judicial a tradução da legislação brasileira para o alemão.

Sob a alegação de não contrair as leis vigentes no Brasil, possivelmente desconhecidas, a prática política refletia a herança revolucionária das décadas de 1830 e 1840 e as utopias que inspiravam jovens e trabalhadores europeus. A comuna foi contestada pelas autoridades do Império, que, não a condenaram, mas recomendaram que fosse criada uma Câmara Municipal.

A partir de 1855 a Direção da Colônia criou a Sociedade dos Proprietários, que no ano seguinte passou a ser denominada de Comuna da Colônia. Procurava-se, desta forma, orientar o foco para o administrativo, em detrimento do político, no sentido de evidenciar o empenho dos colonos na construção e conservação de estradas e pontes, a partir da arrecadação dos seus próprios impostos. A Colônia, segundo Ficker (1965, pp. 171-172), passou a ser organizada em setores, que, agrupados pelo critério da proximidade, formavam distritos. Os distritos formavam unidades autônomas de gestão de recursos e escolhiam um de seus moradores como diretor distrital. O exercício do poder local não se fazia sem conflitos e contradições. Pela documentação recolhida por Magalhães (APMM), é claramente perceptível que os colonos de D. Francisca não costumavam se silenciar diante dos problemas e não temiam fazer suas reivindicações (Correspondência de Aubé, de 25/12/1853). Reclamações como a feita pelos proprietários de terra, em 1866, acerca da estrada que levava ao Paraná evidenciam interesses desencontrados entre administradores e colonos. $\mathrm{O}$ fomento dado pelo governo imperial para a construção da estrada e a possibilidade de ganhos adicionais dos colonos em decorrência dos trabalhos que poderiam prestar à obra resultou em saldo negativo, em razão dos reparos que tiveram que fazer em suas propriedades.
"Desde que a administração foi confiada ao senhor Frankenberg e Parucker, achamo-nos expostos a vexames diferentes e os benefícios do governo imperial são convertidos em males. Com o pretexto de melhorar a estrada, têm-se feito vales enormes dos dois lados da estrada. Por este trabalho, as nossas cercas que houve em frente as nossas terras são desmanchadas e precisamos restabelecê-las por nossa conta. Por estes trabalhos, achamos-nos agora obrigados a construir pontes compridas e largas, para tornar a haver uma comunicação entre os nossos terrenos com a estrada" (APMM).

Os representantes dos distritos formavam o Conselho Comunal que administrou a Colônia até 1872. Com a elevação de São Francisco Xavier de Joinville à categoria de vila, em 1866, e a instalação da câmara municipal, em 1869, evidenciou-se um conflito de poder e de dupla tributação. O jornal Kolonie Zeitung (12/11/1870) traduziu esta 
realidade, registrando que: "Os ensaios de vir a um acordo com a câmara municipal malograram-se, apesar da mediação da direção da colônia, e uma decisão que foi prometida à junta pela comarca municipal em sessão pública até o fim de abril." A Colônia não queria abrir mão da sua organização cívica para submeter-se ao mando político do município de São Francisco. Por outro lado, com a municipalização, os imigrantes que não gozavam dos seus plenos direitos políticos não podiam exercitar a cidadania. "Seria mal para a colonização quando os colonos que aí demonstrassem quererem se naturalizar fossem considerados ilotas, fosse vedado anunciar as opiniões acerca dos negócios comuns, só porque não tem o direito de votar nas eleições como cidadão nato ou naturalizado", registrava Ottokar Dörffel, em sua correspondência, de 12 de fevereiro de 1870, ao Presidente da Província (APMM). As contendas no interior da Colônia haviam levado um grupo dissidente a buscar um novo espaço para a colonização-São Bento(1872/1873). Os colonos de São Bento reivindicavam as mesmas prerrogativas concedidas aos de D. Francisca. Não as obtendo e vendo descumprida a promessa de receberem trabalho e renda na construção da estrada para Curitiba, organizaram movimentos de reivindicação dos pretensos direitos. Alguns se projetaram sobre Joinville. O próprio Diretor da Colônia, Ottokar Dörffel, em correspondência ao Presidente da Província, em 17/03/1874, passou a usar a justificativa:
"que gente de São Bento para cá veio em chusma no intento de fazer uma demonstração não violenta. Muitos colonos confessarão que foram forçados a acompanhar e necessitados para acompanhar. E, com efeito, entre os moradores de São Bento há alguns homens que além do mar foram ensinados pelos Democratas Socialistas, talvez mesmo fossem membros da Internacional" (APMM).

A experiência histórica de D. Francisca (Joinville) na trajetória da construção cívica comunitária evidencia que, além do desafio de superar dificuldades comuns, teve presente um ideário político marcado por um projeto societário que, entre conflitos e desavenças internas, fez prevalecer os espaços participativos, que visavam a garantia de direitos iguais, privilegiando as decisões dos colonos. O exercício da cidadania moveu-se na direção do preenchimento do vácuo deixado pelo Estado, notadamente no que diz respeito às políticas que pudessem contemplar as realidades emergentes no universo da colonização.

\section{O fenômeno da instabilidade político-territorial e as comunidades cívicas de autodefesa}

O medo é um sentimento humano extremo que, segundo Darwin (2009, pp. 248 e 249), pode levar à prostração, à agonia e ao desespero. A ameaça e o medo podem, ao mesmo tempo, despertar o instinto de proteção e estimular arranjos associativos para fortalecer a defesa. Estes sentimentos se fizeram presentes, de certa forma, entre os 
imigrantes, ou pelas ameaças do meio e os conflitos em que eram envolvidos, ou pelos desafios pela sobrevivência. No Rio Grande do Sul, a Revolução Farroupilha (18351845) afetou a vida cotidiana e social dos colonos alemães e de seus descendentes. Alguns deles participaram diretamente das milícias dos farrapos (FLORES, 1995). Os conflitos afetaram as relações horizontais dos membros das comunidades locais, onde os sentimentos de pertencimento ao grupo e de segurança eram cultivados.

Em circunstâncias relacionadas com o processo de expansão da colonização, os colonos se defrontaram com situações inusitadas que envolviam conflitos resultantes tanto do problema das fronteiras étnicas quanto das territoriais. Exemplos como os descritos no romance - As Vitimas do bugre - de Mathias Gansweidt (1946), que relata o seqüestro da família Versteg pelos Caingangues nas imediações dos atuais municípios gaúchos de São Vendelino e Bom Princípio, em 1867, além de desenhar as fronteiras culturais entre os alemães e os nativos, apontam para a imprevisibilidade e o risco que o "outro" representava para a integridade das famílias dos colonos. Caracterizava-se, assim, um estado de medo diante do outro e do ambiente desconhecido e, para evitar o pânico do terror, se fazia necessário o arranjo de impulsos para a promoção de um ambiente de segurança e bem-estar social.

Os conflitos em torno da construção dos territórios familiares e comunitários acenavam, de forma crescente, para a necessidade do exercício da cidadania. O exercício da cidadania exigia, nestas circunstâncias, atitude e, assim, tanto nos territórios familiares quanto nos comunitários, a construção da territorialidade esteve associada às relações intersubjetivas e de poder que se travavam nos espaços de convivência familiar e comunitária.

As demandas políticas do Estado, os conflitos em torno da posse da terra e a autodefesa passaram a exigir assistência jurídica e educação política, para que os colonos pudessem garantir os seus espaços familiares e comunitários e organizar a sua base econômica. Neste sentido, foi de relevante importância à fiança das lideranças da Igreja da Imigração, católica e evangélica luterana, para a organização das comunidades cívicas. Entenderam, em certo momento, que uma ação cívica de inserção cidadã dos colonos se fazia eminente. "A participação política sem vínculo ao governo ou partidos, mas em função dos interesses do seu povo, tornando-se defensora da autoridade, da lei e da ordem", fundamentava o seu discurso (DV, 27/7/1926). A inexistência de garantias legais, os conflitos em torno da posse da terra, as arruaças e invasões de domicílios, as demandas jurídicas e fiscais e as intrigas de vizinhança requeriam participação e representatividade políticas que significassem maior presença institucional do Estado. Uma administração municipal mais próxima e simplificada; maior atenção aos imigrantes, infra-estrutura de estradas e de comunicação, educação agrícola, entre outras aspirações e saltos imaginativos desencadearam o processo criativo da constituição de comunidades cívicas em torno do ideário republicano, vertente política mais simpatizada pelos colonos, em oposição a federalista. Surgiram assim os Clubes Republicanos, no interior de São Sebastião do Caí e de Montenegro. O primeiro deles, fundado em Forrameco (São Vendelino), em 22 de maio de 1890, 
colheu mais 250 assinaturas (KUNERT, 1986, p. 84). A experiência difundiu-se pela região das antigas colônias alemãs, tendo entre seus adeptos alemães, tanto católicos e quanto evangélicos, e italianos.

Com a deflagração da Revolução Federalista de 1893, grupos de federalistas (maragatos) e bandos independentes passaram a invadir a área colonial, causando prejuízos através da destruição de lavouras, do roubo de animais domésticos e de ameaças à segurança das famílias. Diante deste clima de instabilidade social e política, as colônias das regiões de São Salvador, São Benedito, São Vendelino, Bom Princípio e Harmonia organizaram, em setembro de 1893, uma Sociedade de Defesa-Bürgerverein, com a finalidade de garantir a proteção da colônia e a integridade dos indivíduos, da família e da propriedade (DV, 21/09/1894). Dentre os dispositivos estatutários constava a estrutura organizacional da Sociedade, que previa um Comitê Central, composto de uma diretoria, com presidente, vice-presidente e secretário e um líder em cada picada, que, como representante local da associação, integrava também o Comitê Central. Todos os ocupantes de cargos eram eleitos por seus pares.

Foi certamente o ambiente de instabilidade política que mais e de forma crescente despertou a consciência e a necessidade da organização cívica das comunidades teutobrasileiras. As disputas entre os republicanos e os federalistas em torno da hegemonia política do Rio Grande do Sul tiveram novo desdobramento com a Revolução de 1923. Dentre outras postulações, esteve em questão o modelo federativo. Sangrenta, a memória histórica e o folclore tributam a esta revolução lembranças de cenas de arruaça e de terror, atribuídas aos maragatos, sobretudo nas colônias que haviam se expandido de São Leopoldo na direção da Serra Gaúcha. As colônias do noroeste do Rio Grande do Sul e do Oeste de Santa Catarina foram tomadas de sobressalto pela Coluna Prestes, que, em 1924, partiu de Santo Ângelo em direção às fronteiras do oeste do Brasil. A Coluna trouxe um clima de insegurança e medo nas colônias, pelos saques e arbitrariedades cometidos por seus membros.

As ameaças, os saques e os atos terroristas que se projetaram sobre as famílias e sobre as comunidades promoveram a experiência do medo, que, por seu turno, motivou a mobilização em torno da proteção e defesa. Comunidades como as do Vale do Caí, da encosta da Serra Gaúcha, de Santa Cruz e Lajeado que já haviam sentido os efeitos da ação dos maragatos, em 1893, e as da Serra, Planalto e Alto Uruguai que sofreram a ação dos revolucionários de 1923 e da Coluna Prestes, mobilizaram-se em torno da organização de suas próprias milícias para a defesa. Relatos, como o reproduzido pelo Kalender der Serra-Post (1926, pp. 115 e seg), dão conta das barbáries a que eram submetidas as famílias do interior, o que dá sentido à expressão: "O perigo nos uniu e a união nos fortificou e a união e a força nos alertaram e despertaram a nossa atenção".

Os arranjos de autodefesa, ou seja, as Sociedades de Mútua Proteção ou Associações de Autodefesa - Selbstschutzvereine, foram organizadas formalmente a partir de 1922. Estes arranjos foram formados por grupos, que, instruídos e adestrados nas armas, tiveram que seguir rigorosamente a ordem instituída e a hierarquia. Os grupos 
possuíam um comandante superior e comandos seccionais. Seguiam um estatuto próprio e buscavam o seu fortalecimento e a sua autonomia (SCHALLENBERGER, 2009). Prova da sua representatividade foi a realização do encontro dos Selbstschutzvereine, em janeiro de 1924, em Neu-Württemberg (Panambi). Reuniram-se na ocasião, ostentando bandeiras que identificavam as associações, mais de 1.000 associados, com o objetivo de dar maior unidade de ação (Serra-Post, 11 de janeiro de 1924).

A proteção da colônia, o trabalho conjunto para promover a segurança e garantir o trabalho dos colonos eram os imperativos cultuados pelas associações de autodefesa para o fortalecimento do poder local diante das ameaças e de uma possível intervenção externa (Die Serra-Post, 21 de Março de 1924). A exposição ao risco, o medo e a ansiedade são sentimentos que podem conduzir à indignação e, no caso dos colonos, estimular a imaginação, entendida segundo Janson \& Janson (1996, p. 6) como elo entre o subconsciente e o consciente, atuando de forma sistemática para estatuir mecanismos que garantam a confiança mútua enquanto preceito moral para a garantia de valores fundamentais como a família e o trabalho. A defesa da família, da propriedade e do patrimônio comunitário, aguçou o sentido de pertencimento e despertou a consciência coletiva em grau mais elevado, entre os teuto-brasileiros e dos que com eles conviviam nos territórios dos núcleos de colonização. Nestes núcleos, as relações sociais estavam fortemente marcadas pela racionalidade e pela moral do trabalho. Aliás, os referentes simbólicos produzidos em torno da família e do trabalho representaram elementos de distinção em relação a outros grupos externos ás comunidades étnicas (Bourdieu, 2007). A distinção se estabelecia, fundamentalmente, pela rejeição aos hábitos, às práticas culturais e aos estigmas produzidos a partir das revoluções e dos saques às famílias e às comunidades constituídas a partir da imigração e colonização.

Dos conflitos e da violência física se originaram a insegurança e o medo, que passaram a expressar outro conflito: o da violência simbólica. A violência simbólica nasceu de um conjunto de ameaças externas, despertando nos sujeitos sociais da colonização a necessidade de demarcar os limites culturais, expressos, sobretudo, pela distinção nas práticas e nos hábitos sociais. A distinção favoreceu, por seu turno, a unificação da representação e da expressão dos interesses das comunidades étnicas, tanto que organizaram comissões representativas dos diferentes núcleos coloniais com a missão de apurar os prejuízos causados e para, a partir das suas estimativas, reivindicarem do Estado os reparos (Die Serra-Post, 4 de julho de 1924).

\section{O fenômeno do mercado, as comunidades cívicas e a cooperação}

Se a autodefesa representou um movimento de articulação local dos colonos, onde razão e sensibilidade encontraram, em face da necessidade de segurança e proteção, uma possibilidade de garantia da liberdade, outras formas de organização associativa se tornaram imperativas em face da necessidade de promover maior estabilidade econômica e bem-estar para as famílias e as comunidades. A fragilidade da base agrícola de subsistência tornava os agricultores reféns das intempéries, das irregularidades do 
mercado e das demandas individuais e sociais. Lideranças vinculadas às igrejas da imigração (católica e evangélico-luterana) e às escolas comunitárias entenderam que se faziam necessárias ações envolventes em termos de instrução, formação e práticas culturais, que, pela elevação da auto-estima, pudessem promover a articulação dos sujeitos sociais num cenário de conflitos políticos e de instabilidade social e econômica.

"Precisamos encontrar os caminhos legais para alcançar os nossos objetivos" (DV, 25/10/1923) e para "defender a firme tradição alemã não devemos contra-atacar simplesmente. Jamais se consegue conquistar objetivos com armas de fogo. Deve-se procurar o caminho das leis, nas organizações, nas eleições, no esclarecimento político" (DV, 23/04/1923). O apelo à inclusão cidadã buscava uma mobilização capaz de um envolvimento em ações que assegurassem maior participação na defesa e promoção dos interesses dos teuto-brasileiros. Foram instituídas, neste sentido, assessorias para prestar serviços de acompanhamento jurídico, de esclarecimento e orientação legal e editados pequenos manuais de orientação político-eleitoral. O objetivo era cercar as iniciativas de natureza social e política de garantias legais, para evitar retaliações, a exemplo das sofridas durante a I Guerra Mundial e nas revoluções do final do século XIX e da segunda década do século XX, e garantir um desenvolvimento autônomo, que assegurasse direitos e valores não legitimados pelo Estado.

A educação continuada se fez presente em várias instâncias das comunidades teuto-brasileiras, pela difusão de valores e práticas culturais que estimulassem a participação democrática e o fortalecimento das comunidades (étnicas). Os chefes de família eram envolvidos na organização e gestão comunitária, na vida associativa de natureza cooperativa e sindical e em comissões que buscavam prover a constituição dos espaços coletivos e a infra-estrutura necessária para as demandas das comunidades locais. As senhoras eram motivadas, sobretudo, para o desenvolvimento de ações que dessem resposta às demandas da saúde e da assistência social. Os jovens eram orientados a constituir grêmios para desenvolverem a leitura, a disciplina e habilidades sociais e políticas para o exercício da participação democrática e para o respeito à hierarquia. A utopia social que espelhava estes interesses e ações reflete um modelo de organização social concebido a partir de núcleos familiares sólidos, articulados em torno de comunidades coesas, fundadas em relações de solidariedade e cooperação. Independente de confissão religiosa, a evocação do princípio ideológico associado à etnia de que "a organização das comunidades é talento nato dos alemães e nele reside a possibilidade de afirmação política e social" (DV, 23/05/1924), expressa, para além da fronteira cultural, a forma de apropriação e organização territorial. Mesmo que não se trate da afirmação de uma totalidade étnica, evidenciam-se valores societários fundados na tradição étnico-cultural que caracterizam um modelo de organização social. É de certa forma o sinal da distinção, ou seja, a demarcação das fronteiras culturais. O Omnia Omnibus (tudo para todos), slogan derivado do ideário do associativismo cristão, referia-se, no entanto, à unidade de referência sociocultural teuto-brasileira enquanto totalidade possível. 
A conversão deste ideário em formas de organização social e produtiva resultou na constituição de uma gama de associações, dentre as quais as mais expressivas foram: Associação Rio-Grandense de Agricultores - Bauerverein -, fundada em 1900; as Uniões Coloniais, que resultaram do modelo descentralizado da Associação dos Agricultores; e, a Sociedade União Popular para os Alemães Católicos do Rio Grande do Sul - Volksverein -, fundada em 1912, que teve ramificações em Santa Catarina e no Paraná, e da Liga das Uniões Coloniais, fundada em 1929. Estas organizações pautaram as suas ações nos princípios da cooperação, da assistência social e educacional, da solidariedade étnica, da colonização e da organização e defesa dos espaços familiares e comunitários (SCHALLENBERGER, 2009).

Tanto a Associação Rio-Grandense de Agricultores, quanto suas sucedâneas, União Popular e Liga das Uniões Coloniais, foram constituídas a partir de um forte componente religioso, vinculado à tradição étnico-cultural das comunidades cristãs. Num primeiro momento, os mediadores sociais da colonização fizeram prevalecer os elementos étnicos sobre os confessionais, pelo entendimento de que "a segurança econômica dos colonos alemães somente poderia ser efetiva, através de uma organização interconfessional da população teuto-brasileira" (DEB, mar./abr. 1934, p. 3 e 4). É com este espírito que a Associação Rio-Grandense programou um modelo de organização social estruturado em uma rede de associações - Uniões Coloniais -, espalhadas pela grande maioria das colônias da imigração. No ano de 1931, 118 delas estavam estruturadas nos espaços da imigração sul-rio-grandense e reuniam um total de 17.000 associados (Noticiário, maio de 1931). As Uniões Coloniais se caracterizaram como comunidades cívicas que aproximaram, cada vez mais, os colonos das esferas política e econômica, na perspectiva da sua recidadanização e da sua inserção social e produtiva no conjunto da sociedade brasileira. Observadas nesta perspectiva, se transformaram em canais de interlocução e de reivindicação, assumindo a função de sindicatos.

As Uniões Coloniais eram importantes instrumentos de organização do poder local. Estimularam o surgimento de Associações de Assistência Jurídica e Legal Rechtsbeihilfe Vereine - postularam espaços de representação política e fomentaram ações voltadas para a efetiva aproximação com os representantes da esfera pública, visando o desenvolvimento das comunidades (Die Serra-Post, 1 de abril de 1924). A articulação dos sujeitos sociais em torno das Associações para promover a defesa dos interesses econômicos, a inserção produtiva e a valorização do trabalho e da produção, resultou na organização de cooperativas, que, no início da década de 1930, chegaram ao expressivo número de 339 sociedades cooperativas das mais diferentes modalidades de produção (banha, leite, fumo, vitivinicultura, agropecuárias e mistas) e em torno de 50 cooperativas de crédito (SCHALLENBERGER, 2009). Esta ação representa, sem dúvida, a maior expressão material da contribuição das Uniões Coloniais para o desenvolvimento regional.

As práticas de cooperação, associadas à moral e à racionalidade do trabalho, contribuíram para estabelecer uma forma de distinção em relação aos setores tradicionais 
da economia regional, organizados em sindicatos. Os empreendimentos comunitários e cooperativos favoreceram a organização da produção nos espaços da colonização, contribuíram com a inovação tecnológica e com o aumento da produtividade, estenderam o crédito agrícola ao colono, incrementaram uma rede de comercialização da produção e fomentaram o desenvolvimento comunitário. A inovação tecnológica esteve centr1As Uniões Colônias, lideradas pela Liga das Uniões Colônias, constituída em 1929 para representá-las, buscavam se adaptar a política governamental, estimulando a produção para o abastecimento do mercado e da indústria. Esta postura gerou desconfiança e indignação dos integrantes da vertente católica do associativismo do sul do Brasil, que liderou a constituição da Associação Rio-Grandense de Agricultores, dela se separando em 1912 para constituir a Sociedade União Popular para os Alemães Católicos, por entender que o caminho da organização social não comportava a subordinação do religioso ao político. $\mathrm{O}$ discurso católico se referia à consciência política enquanto instrumento de defesa do ideário social católico frente o avanço das ideologias liberal e comunista, o que se evidencia no dizer do Secretário de Viagens da Sociedade União Popular, Josef Otten, reproduzido pelo jornal Deutsches Volksblatt (3/06/1914): “A situação não deve chegar a ponto dos católicos terem que lutar por sua religião, igreja e escolas (...). A liberdade é a senha dos católicos: liberdade de culto, liberdade no exercicio da sua cidadania e da religião".

A Sociedade União Popular era constituída por uma rede de associações que combinavam a dimensão cívica com a religiosa, já estudada por mim anteriormente (SCHALLENBERGER, 2009). Os estatutos da Sociedade União Popular, ao assegurar que "a língua da Sociedade é a alemã (...), que todos os alemães falantes que completaram 18 anos poderão associar-se a Sociedade e que na sua posição de seguir as obrigações religiosas, a Sociedade conscientemente seguirá os princípios postos pelo papa", definem como elementos de distinção cultural a língua e a religião. Apesar e por conta de sustentar uma utopia social própria - social-catolicismo - a religião organizada não pode ser entendida, neste caso, como elemento integrante da comunidade cívica, mas uma alternativa à sua constituição (PUTNAM, 2007, p. 120). A Sociedade União Popular esteve alicerçada na organização eclesiástica, onde, segundo disposição estatutária, "em toda paróquia onde a Sociedade é aceita será formado um distrito e em toda capela ou escola comunitária haverá uma secção" (DV, 14/03/1914). A sua base organizacional esteve, portanto, assentada em secções, que reunidas formavam os distritos e que, geralmente, coincidiam com as paróquias. Havia escritórios regionais vinculados à Central do Volksverein, com sede em Porto Alegre. Possuía uma diretoria, um Secretário Itinerante, os secretários das regionais, e as diretorias distritais e seccionais. Não havia transcorrido um semestre desde a sua fundação, a União Popular já esteve organizada em 39 distritos, com um total de 2.277 associados (SP, $\left.n^{\circ} 2,1912\right)$. Em 1914, já contava com 60 distritos e chegou a atingir o patamar de 10.000 sócios, em 1934.

Reforçando o que já escrevi anteriormente (Schallenberger, 2009), respeitadas as diferenças e as estratégias, quando a etnicidade era posta em questão ou quando 
as comunidades étnicas sofriam ameaças as Uniões Coloniais e a Sociedade União Popular partilhavam posições, mais pela iniciativa de seus membros do que dos seus dirigentes. No campo político a União Popular ensaiou, sem expressão maior, caminho próprio, buscando imitar o Partido do Centro da Alemanha - Zentrum Partei -, que representava a força integradora do catolicismo (HOFFMANN, 1993, p. 108). A consciência da necessidade de uma maior participação política despertou quando os teuto-brasileiros efetivamente vislumbraram a possibilidade de ter seus representantes nas diferentes instâncias do poder político. O crescimento das vilas e o processo de municipalização chamaram à arena política - que tinha suas próprias regras - os sujeitos sociais e com eles as associações que representavam. Inseridos nas comunidades locais, manifestaram a vontade de ter representação nas instâncias do poder federal e estadual e o desejo de influir na administração dos próprios municípios, "através da eleição de homens como intendentes e conselheiros da Câmara, que votem e sejam fiéis aos seus co-cidadãos, que conheçam as necessidades do seu município e que estejam dispostos a ajudar e a representar os mesmos" (DV, 5 de abril de 1924).

\section{Considerações finais}

As experiências históricas da construção cívica comunitária nos espaços da colonização alemã do sul do Brasil evidenciam que os colonos, além do desafio de superar dificuldades comuns, despertaram a consciência em torno um ideário político e de um projeto societário que, entre conflitos e desavenças internas, fizeram prevalecer os espaços participativos para valorização cidadã e revitalização dos valores e das práticas culturais. O exercício da cidadania moveu-se na direção de uma fronteira não definida em termos institucionais e de políticas públicas, o que fez com que a materialização do ideal societário se desse a partir dos elementos de distinção da cultura dos imigrantes. As vivências derivadas da produção social do espaço despertaram sentimentos de justiça, de solidariedade e de pertencimento a um todo social organizado e que não eram alimentados pelo Estado.

Os desafios decorrentes das privações e das realidades emergentes no universo da colonização podem ser evocados como elementos importantes para a definição e identificação dos interesses comuns e motivação para a organização das comunidades cívicas entre os imigrantes alemães e seus descendentes. Identificados em seu patrimônio simbólico e em seus ideais societários viram-se cercados de necessidades de amparo e fomentaram a sociabilidade e a construção de relações horizontais de solidariedade e cooperação.

A organização comunitária era concebida como um espelho da família e, portanto, deveria privilegiar espaços de participação para todos os seus membros.

Linguagem e arte, religião, tradição familiar e comunitária, práticas culturais e racionalidade e ética do trabalho são elementos de distinção que desenharam as fronteiras culturais dos grupos de imigrantes alemães e seus descendentes no sul do Brasil. 


\section{Referencias Bibliográficas}

Almeida, R. P.; Piazza, M. F. F. (orgs.),1979. “A Comuna da Colônia Dona Francisca”. UFSC Departamento de História, Florianópolis, (mimeo).

Barth, F. 1998. "Grupos étnicos e suas fronteiras". In P. Poutignat, J. Streiff-Fenart (eds.), Teorias da etnicidade, UNESP, São Paulo, 1998, pp. 187-227.

Bauman, Z. 2003. Comunidade: a busca por segurança no mundo atual. Trad. P. Dentzien, Jorge Zahar, Rio de Janeiro.

Bourdieu, P. 2001. O poder simbólico. Bertrand do Brasil, Rio de Janeiro.

Bourdeiu, P. 2007. A distinção. Zouk, Porto Alegre.

Bourdieu, P. 1982. A economia das trocas simbólicas. Perspectiva, São Paulo.

Bourdieu, P. 1997. "As contradições da herança”. In D. Lins (ed.), Cultura e Subjetividade: saberes nômades. 3 ed, Papirus, Campinas.

Carrion Jr., F. M. 1979. "Economia do Rio Grande do Sul”. In J. H. Dacanal, S. Gonzaga, RS: economia e política. Mercado Aberto, Porto Alegre.

Coaracy, V. 1957. A Colônia de São Lourenço e seu fundador Jacob Rheingantz. Saraiva, São Paulo.

Ficker, C. 1965. História de Joinville. Imra Ipiranga, Joinville.

Figueiredo, J. E. S. 2001. Comunidade cívica, capital social e Conselhos de Saúde no Estado do Rio de Janeiro. Dissertação, Rio de Janeiro, Escola Nacional de Saúde Pública da Fundação Oswaldo Cruz.

Flores, H. A. 1983. Canção dos imigrantes. EST, Porto Alegre.

Gansweidt, M. 1946. As vitimas do bugre. Selbach, Porto Alegre.

Gertz, R. E. 2005. O Estado Novo no Rio Grande do Sul. Editora da Universidade de Passo Fundo, Passo Fundo.

Gonçalves, M. 2008. "Missionários da boa imprensa". Revista Brasileira de História, 28 (55), pp. 63-84.

Hofmann, R. 1993. Geschichte der deutschen Parteien. R. Piper GmbH \& Co, München.

Janson, H. W., Janson A. F. 1996. Iniciação à história da arte. 2 ed., Martins Fontes, São Paulo.

Kunert, U. I. 1986. "Tentativas de organização política na Colônia Alemã de São Sebastião do Caí”. Anais - Simpósio de História da Igreja, São Leopoldo: Sinodal/Rottermund, pp. 86-88.

Macpherson, C.B. 1977. A Democracia Liberal-Origens e Evolução. Zahar Editores, Rio de Janeiro.

Magalhães, M. B. de. 1998. Pangermanismo e nazismo. A trajetória alemã rumo ao Brasil. EdUNICAMP/FAPESP, Campinas.

Martins, J. de S. 2009. Fronteira: a degradação do outro nos confins do humano. Contexto, São Paulo.

Oliveira, R. C. de. 2006. Caminhos da identidade: ensaios sobre etnicidade e multiculturalismo. UNESP, São Paulo.

Putnam, R. D. 2007. Comunidade e democracia: a experiência da Itália moderna. (Trad. L. A. Monjardin), 5 ed., Fundação Getúlio Vargas, Rio de Janeiro. 
Rambo, A. B. 1994. A escola comunitária teuto-brasileira. UNISINOS, São Leopoldo.

Rambo, A. B. 1988. "O associativismo teuto-brasileiro e os primórdios do cooperativismo no Brasil”. Perspectiva econômica, 23 (62-63), pp. 3-272.

Schallenberger, E. 2009. Associativismo cristão e desenvolvimento comunitário: imigração e produção social do espaço colonial no sul do Brasil. Edunioeste, Cascavel.

Tocqueville, A. de. 1998. A Democracia na América. Martins Fontes, São Paulo.

Thompson, P. 1992. A voz do passado: historia oral. Paz e Terra, Rio de Janeiro.

Vargas, G. 1938-1947. A nova política do Brasil. José Olympio, Rio de Janeiro, 11 v.

\section{Periódicos}

DEB - Deutsches Evangelische Blätter für Brasilien, São Leopoldo, Rotermund, edição mensal de 1919-1938.

Die Serra-Post. Ijuí, Livraria Serrana, edições a partir de 1922.

DV - Deutsches Volksblatt, São Leopoldo, 1871-1891; Porto Alegre, 1891-1940.

Kalender der Serra-Post, Ijuí, Löw e Becker, a partir de 1922.

Koonlie Zeitung, Joinville, 1862 em diante.

Nachrichtenblatt der Liga das Uniões Coloniais Riograndenses, São Leopoldo, Rotermund, edição mensal de jun. 1931- ag. 1932; bimensal de set/out. 1932 - jul./ag. 1939.

Noticiário - órgão da Liga das Uniões Coloniais Riograndenses (versão vernácula do Nachrichtenblatt), São Leopoldo, Rotermund, mensa 1 de jun. 1931 - ag. 1932; bimensal de set./ot./ 1932 - jul./ag. 1939.

Sonntagsblatt für die evangelischen Gemeinden in Brasilien, São Leopoldo, 1888-1939.

SP - Skt Paulusblatt, Porto Alegre, Tipografia do Centro, a partir de 1912.

APMM - Arquivo Particular de Marionilde Brepohl de Magalhães. 